\title{
A Conceptual Model for a Safety-Based Theory of Lean Construction
}

\author{
Soheila Moaveni ${ }^{1}$, Seyed Yaser Banihashemi ${ }^{1}$ (D) and Mohammad Mojtahedi ${ }^{2, *(D)}$ \\ 1 Civil Engineering Dept., Ferdowsi University of Mashhad, Mashhad 9177948974, Iran; \\ smoaveni@mail.um.ac.ir (S.M.); y.banihashemi@um.ac.ir (S.Y.B.) \\ 2 Faculty of Built Environment, University of New South Wales (UNSW), Sydney 2052, Australia \\ * Correspondence: m.mojtahedi@unsw.edu.au; Tel.: +61-450283994
}

Received: 29 November 2018; Accepted: 11 January 2019; Published: 16 January 2019

\begin{abstract}
The construction industry is one of the most fatal industries, so it is important to pay more attention to safety solutions. Even though work-related accidents are known as a major waste in construction projects, little attention has been paid so far to incorporating safety into the lean construction framework. In this research, lean construction theory is reviewed through the lens of safety. That being so, the identified challenges in previous research on improving safety in construction projects are categorized, and those related to the concept of lean project delivery are introduced. Then, the principles of the lean construction framework are explained, and the relevant changes for incorporating safety into the framework are introduced and discussed. The proposed model includes a new approach to the Transformation-Flow-Value framework, in order to pay particular attention to safety in construction projects as one of the factors affecting the success of projects, and achieving optimal value for stakeholders. It is expected that this hybrid model would further enrich the lean construction framework. The careful attention of project executives to this model may improve the safety situation in construction projects. The conceptual model presented in this study can be used in the decision making process for project managers as well as research into optimization of safety costs, and eliminating waste (including models for optimizing the movement of machinery, controlling and reducing rework, and designing the site layout).
\end{abstract}

Keywords: Prevention through Design; Safety Climate; Lean Construction; Transformation-Flow-Value; Lean Project Delivery System

\section{Introduction}

Despite extensive research on safety in the construction industry, incidents are still one of the main problems of the industry, and the mortality rate is about five times the average of other industries [1], causing about an 8 to 15 percent increase in project costs in countries such as the United States [2]. With regard to these consequences, some researchers have focused on proactive and preventive approaches, such as safety climate or Prevention through Design (PtD), which can prevent the occurrence of about $40 \%$ of accidents [3]. In addition, some of the benefits mentioned by Manuele [4] regarding the use of PtD include: "improved productivity, decreased operating costs, significant risk reduction, and avoidance of expensive retrofitting".

On the other hand, building construction often occupies the bottom of industrial productivity rank reports worldwide [5]. Over the past few years, many solutions have been proposed to address productivity problems in the construction industry. In addition, the success of lean production has caused researchers in the construction industry (despite the differences between production and construction) to become interested in the implementation of these principles within the construction industry. The term "lean" is attributed to John Krafcik [6] to describe Toyota's production methods, 
indicating a new form of production, because it uses less human effort, less manufacturing space, less investment in tools, and less time spent on new product development, but generates high quality, less inventory, and a greater variety of products [7]. In this regard, researchers such as Koskela [8] acknowledged that the traditional construction system needs to be transformed by the concept of lean construction, and that it should be converted, streamed, and managed, to improve the performance of construction projects. Consequently, in 2000, Koskela introduced a new theory of production called Transformation-Flow-Value (TFV), which resulted in the integration of the three theories of transformation, flow, and value creation. He believed that the integration of these three theories could create a key solution to the problems of construction. In fact, any system in the field that pursues the TFV's goals is approaching the lean system [9].

Various studies have been done on the impact of lean techniques on project performance. A study conducted in the USA by Salem et al. [10] shows that a project that implemented lean construction techniques was completed under the budget and three weeks ahead of schedule. In addition, the satisfaction of the subcontractors have also increased significantly, due to communications with the general contractor. Nahmens et al. [11] also showed that after applying lean techniques, job satisfaction in the US industrialized homebuilding sector was elevated by $11 \%$. Thus, various research on lean construction in different countries shows that the successful application of lean principles in construction can improve cost structure [10], delivery times [12], productivity [13], quality [14], plan reliability $[15,16]$, the relationship between working partners $[10,17,18]$, and job satisfaction [11].

On the other hand, in recent years, some studies have studied the impacts of lean construction techniques on the safety performance of projects [19-23], and as a result, there is enough evidence showing that lean techniques provide better safety records in comparison with traditional methods [20,22,24,25]. For instance, in 2017, Howell et al. demonstrated that one of the reasons that lean projects are safer than other projects is respect for people, "both through planning and preparation, and through intercepting errors before they cause harm". In other words, issues such as respect for people and psychological safety, and preventing the entry of workers into hazardous situations by delegating power to workers to stop work while observing the error, improve the safety of lean projects compared to other projects [22]. Moreover, Schafer et al. [19] acknowledge that acquiring a reliable workflow (which is vital for the successful implementation of lean construction) is not achieved without safe work practices. Therefore, the results of previous research show that, in addition to implementing lean techniques, it can improve safety and prevent accidental events; safe working methods are also needed to implement the lean techniques ideally. In other words, despite the fact that in past research, the relationship between lean production and safety has been empirically taken into consideration, but the relationship between these two issues and the potential dependency of these have not been addressed to each other. So, there is a lack of comprehensive approach that explains the relationship between the lean construction framework and safety improvements. Accordingly, this study attempts to introduce a conceptual model by reviewing the theory of Transformation-Flow-Value (TFV) with a safety approach for demonstrating the relationship between this theory, and improving safety in the construction process. Therefore, the purpose of this model is to introduce a comprehensive decision-making approach for achieving the goals of both safety plans and lean approaches. In other words, through the model presented in this paper, it can be expected that the decisions, techniques, and goals that are in the lean approach are prioritized, but their implementation, regardless of safety in the project, can negatively affect safety (and vice versa), and can make the most optimal decision based on the value defined by the customer, and through a comprehensive and integrated approach.

At first, the literature on safety issues, and more specifically the PtD approach, safety climate, and Cost of Safety $(\mathrm{CoS})$ are investigated, and barriers to PtD implementation and factors affecting the positive safety climate are extracted. Then, the theory of TFV in lean construction is studied, and the Lean Project Delivery System (LPDS) and its benefits are reviewed. Finally, the relationship between 
LPDS with PtD and the safety climate, and the TFV approach based on safety, will be presented in the form of a conceptual model.

Most of the research in the field of lean construction and safety point to the positive effects of the techniques and principles of lean construction on project safety. In other words, the effect of lean construction on safety has been investigated in previous studies. However, in this paper, the two-sided relationship of lean construction and safety, and the significance of considering safety in achieving the goals and principles of lean construction are considered. In addition, it has been shown in this paper that some of the obstacles to implementing PtD and safety climate can be addressed through LPDS. In other words, as other studies have acknowledged, project safety can be improved through lean construction. However, the remarkable point in the proposed model in this paper is that regardless of safety, the implementation of lean construction seems to be incomplete; because the waste from the incidents in construction projects is very significant, they are not considered as a type of the lean construction waste. In addition, some decisions regarding the implementation of the principles and techniques of lean construction, regardless of safety, can jeopardize the goals of achieving the highest value for the customer, and reducing the losses. Therefore, the most important contribution of this paper is to present a new perspective on the relationship between safety and lean construction, and that in addition to the fact that lean principles can lead to safety, attention to safety in the framework of TFV can also lead to different and more optimal decisions, and eventually more value and less waste in the project could be achieved.

\section{Safety in Construction Projects}

Over the past decade, the focus for safety improvement has been changed from using passive to active measures, such as safety climate. This shift has happened by understanding that organizational, managerial, and human factors are the main culprits of the construction industry's incidents, rather than purely technical factors [26]. Numerous studies have been done on the effects of safety culture and safety climate on safety outcomes. Wiegmann et al. [27] described the climate of safety as a psychological phenomenon, which includes the general understanding of team members of the safety situation at a specific time in the workplace. Mohamed [28] identified 10 potential factors that could affect the safety climate of Australian construction projects; including: (1) management commitment; (2) communication; (3) employee participation; (4) supportive environment; (5) personal awareness of risks; (6) work pressures; (7) supervisory atmosphere; (8) risk assessment; (9) competency of employees; (10) safety rules and regulations. A positive and constructive safety climate is created when appropriate interactions between project partners and project team members are created, to support safety at the front-end of the project. Results of research conducted by Gao et al. [29] show that organizational safety climate is dependent on supervisor safety climate and coworker safety climate. Additionally, they believe that "a positive safety culture should be established both at the organizational level and the group level. Efforts from all top management, supervisors, and coworkers should be provided to improve safety performance in the construction industry".

On the other hand, according to Howell et al. [22], there are two basic ways to prevent injuries: (1) prevention through design, and (2) prevention through task planning. In other words, improving product design and construction planning can play a decisive role in preventing incidents in the project. While a large percentage of safety research has focused on the construction phase of the projects, much less attention has been paid to the early phases, including the planning and design phases $[23,30]$. Research findings in this area indicate that safety planning and careful attention at the pre-construction stages have significant impacts on safety in terms of reducing the incidents throughout the life cycle of the project [3,31,32]. For example, Abdelhamid and Everett [33] proposed a model for identifying the root causes of accidents which could provide a template for systematic and rapid determination of areas requiring more investigations, so that labor and management may put more effective measures in place for preventing probable accidents. Safety in Design (SiD) or Prevention through Design $(\mathrm{PtD})$ can be defined as "the integration of hazard analysis and risk assessment 
methods early in the design and engineering stages, and taking the necessary actions to keep risks of injury or damage at an acceptable level" [4]. Gambatese \& Hinze [34] indicated that the use of knowledge of construction workers and designers in the early stages of a project can be a positive step towards improving safety performance. Another problem is the designers' reluctance to engage in safety, due to the avoidance of litigation and claims [31]. Having this said, the clients can play an active role in safety improvements by choosing an appropriate contract method, since the emphasis on safety during the contracting phase with a contractor or designer has a significant impact on their safety performance $[31,35]$. Some studies have also shown that the contract type has an impact on safety performance. For example, Huang [35] showed that Design-Build contracts have better safety practices, since in these types of contracts, the contractor and the designer play on the same ground, and the design team has more motivations to devise safe plans in the design phase.

The effective and optimal use of preventive approaches to achieve the best results can be estimated through the concept of CoS. Most of clients believe that spending money on safety does not create value for their business, unless it is required by governmental regulations and standards [36]. This view has made problems for safety managers with providing financial justification for the investments. The most common and effective cost model that has been developed to describe the cost-benefit concept of accident prevention is the CoS model [37]. Behm et al. [38] used Cost of Quality (CoQ) classification for categorizing the safety cost into four categories of prevention and inspection costs, and internal and external failure costs. They studied the CoS model in several case studies, and the results showed that the accident prevention strategy provides an optimum safety cost plan. As shown in Figure 1, the cost of safety is equal to the total cost of prevention and inspection, and direct and indirect costs of damage and the optimal point occurred at the intersection of two charts, although the location of this point can vary in different projects [39].

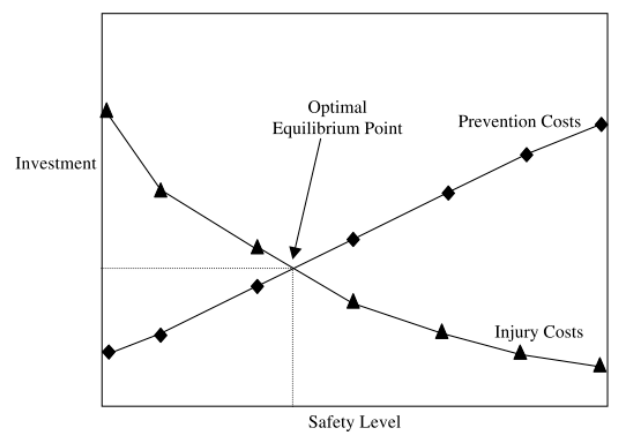

Figure 1. Cost of Safety Model [38].

\section{Lean Construction}

In general, the purpose of a lean approach is to create the highest value for the customer, and to reduce or eliminate waste. Koskela [9] introduced a new theory of production in the construction context, called TFV, which resulted in the integration of three theories of transformation, flow and value creation. In this theory, transformation means the conversion of input into output in production, and the management method is based on using the hierarchical transformation of smaller components (Figure 2A). However, this method has limitations in recognizing the original source of value in the conversion process which is the extent to which the conversion is adapted to the customer's needs and demands. Also, there is a weakness in how to avoid loss and to ensure customer satisfaction.

The flow view considers production as a stream of materials, and a combination of transformation, inspection, moving, and waiting (Figure 2B). In this view, in order to achieve the main goal of eliminating waste, some methods are used to reduce the production process time (lead time), reduce variability, and increase simplification [9,40]. Gunduz and Naser [41] showed that using Value Stream Mapping (VSM) (a method for identifying non-value-added activities in the workflow) in Underground Pipeline Construction Projects can reduce costs by about $20 \%$. 
Finally, in the value creation view, the creation of the highest possible value is measured by taking into account the customer's expectations (Figure 2C). Andújar-Montoya et al. [42] believe that the solutions that have been presented so far to achieve value for the end-user are focused on the design phase, and as a result, the processes carried out in the work execution are inefficient. Therefore, they have developed a framework for "the integrated management in the work execution, which will address change management introduced by users who offer an efficient and productive model that reduces costs in the process"

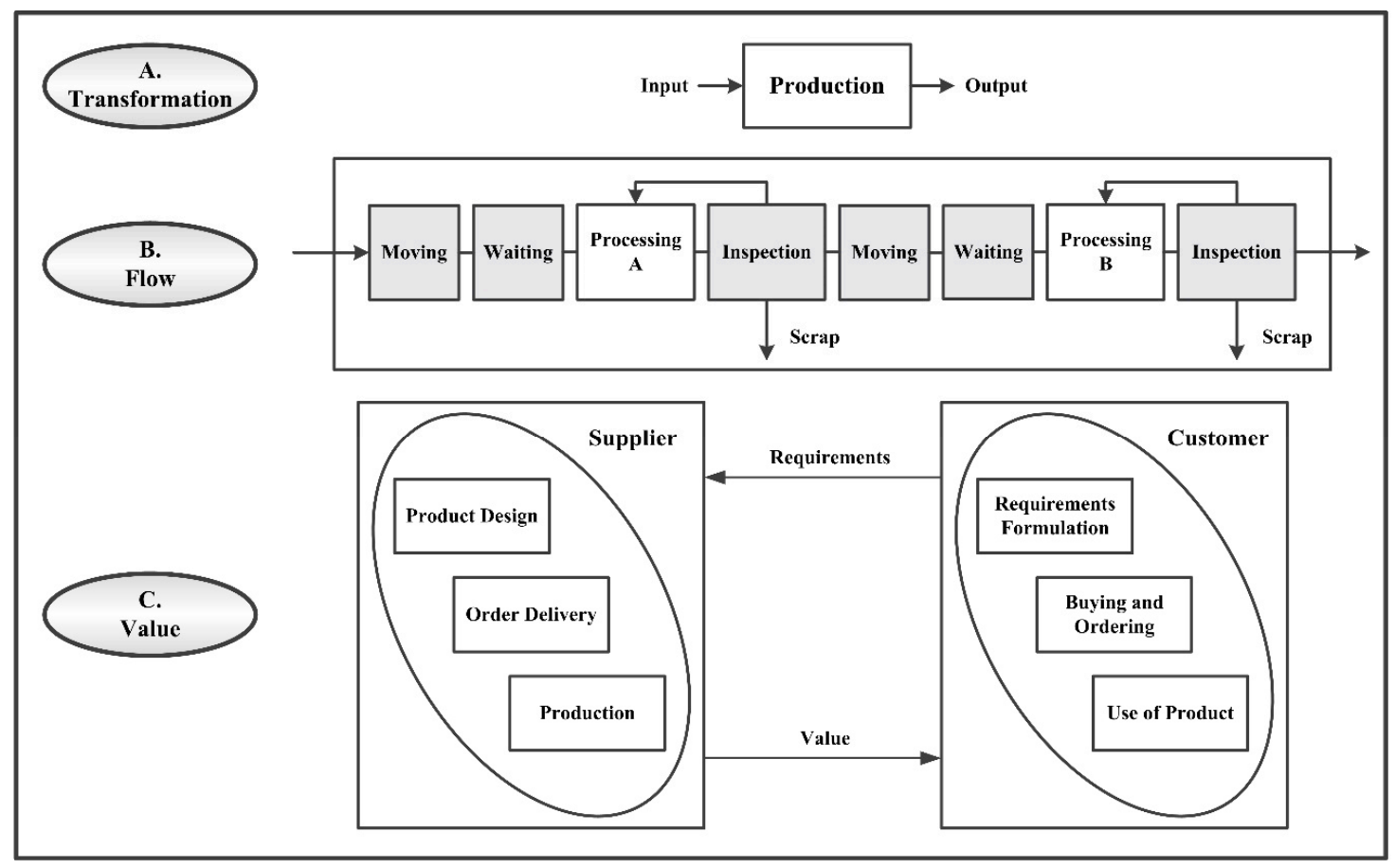

Figure 2. Transformation, flow and value creation $[9,43]$.

In this perspective, the endeavor is to identify the customer's needs by adopting appropriate methods and tools, and creating the expected value for the customer by defining the appropriate processes for designing, ordering, and producing. The theory that integrates and combines the three above-mentioned views is the TFV theory, and any system in the field that pursues the TFV's goals is approaching the lean system [9]. On the other hand, it is difficult to maximize value and to reduce waste at the project level, when the contractual structure impedes the coordination and creativity of project team members. Therefore, choosing the right method of procurement can help to overcome many of the construction problems. In this regard, the LPDS has been defined as a lean approach to designing a delivery system. LPDS, which was presented by Ballard [18] aims to form an expert team in the early stages of the project, driven by principles such as collaboration, trust, communication, transparency, and the use of the best available technology for achieving optimal project success [44].

\section{Lean Construction and Safety Performance}

As explained, the adoption of preventive approaches to the design and planning processes can play a decisive role in improving safety in the construction and operation phases of the project. The question now is how the barriers to implementing preventive approaches, including negative safety climate, the knowledge gap between designers and contractors, the lack of interactions between project participants in the early phases, and the litigation risks among key stakeholders can be resolved.

Previous research showed that lean techniques and practices have the potential to improve the safety performance of projects, and reduce accidents as noticeable sources of waste $[21,23]$. For example, Nahmens \& Ikuma [20] showed that continuous improvement, which is embedded in 
the lean approach, can significantly reduce the rate of accidents in construction projects. The lean perspective can also help to manage safety, which is dependent on the management of uncertainty, as it contributes to preventative planning and reducing work flow variability [21].

On the other hand, LPDS can prompt all key stakeholders to participate actively in the risks and benefits of the project, and to consider themselves part of a team and become sensitive to the performance of other members [17]. As a result, LPDS not only has the potential to promote a positive safety climate in the project, but can also improve the PtD performance by providing the opportunity for two-way communications between designers and contractors, and transferring knowledge and experience between them (Figure 3).

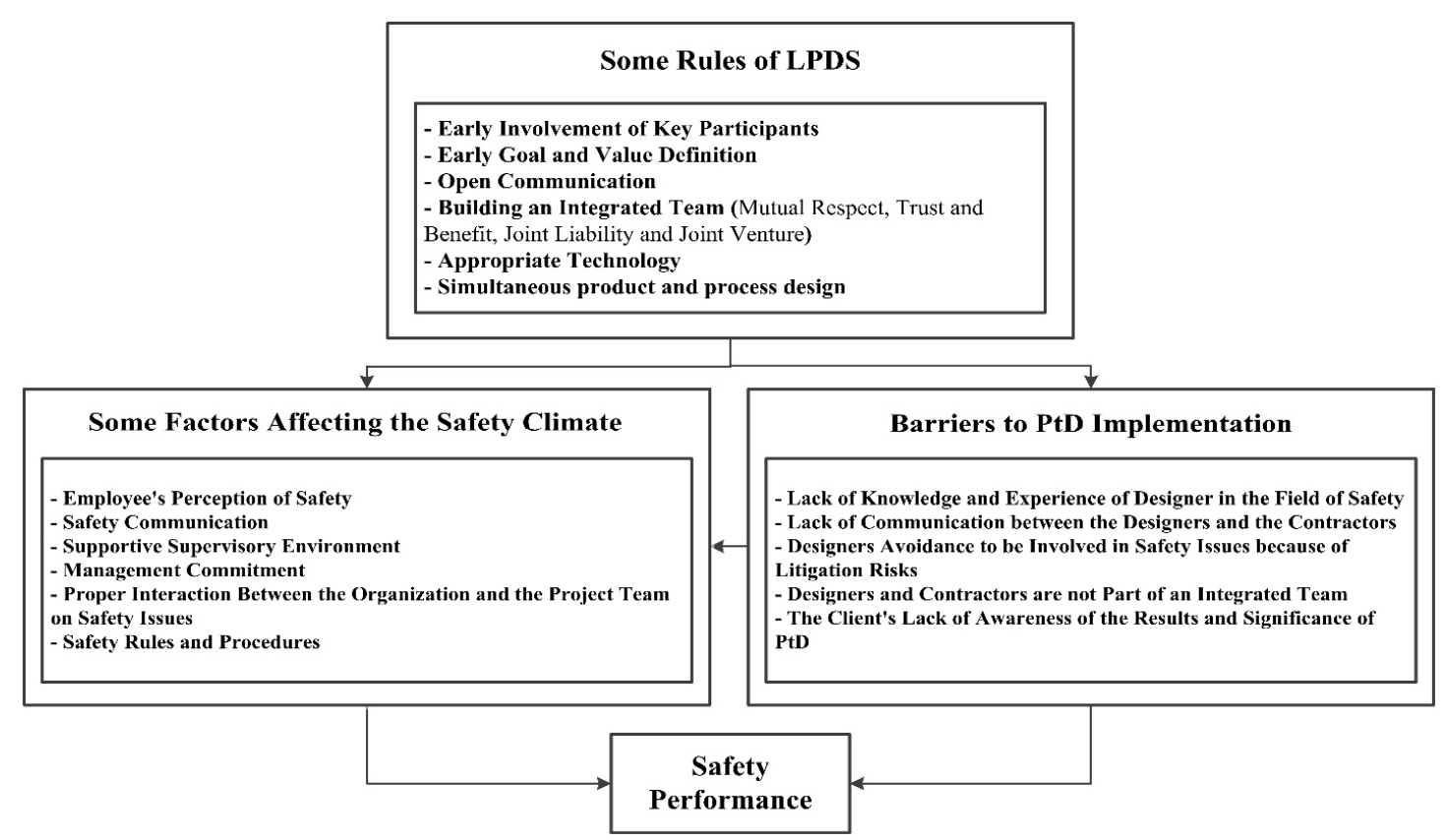

Figure 3. Improving safety performance through the Lean Project Delivery System (LPDS).

In addition, given the fact that one of the principles of LPDS is the simultaneous design of the product and the process, adopting preventive approaches at the early stages of the project would be more probable, and safety risks can be identified and mitigated more effectively [40]. As mentioned earlier, despite studies on the effect of the lean approach on improving safety performance, the effect of incorporating safety in the principles of lean theory has not been studied. So, we will try to examine possible changes in any of the transformation, flow, and value approaches, by examining the theory of TFV from the perspective of safety, and in the context of LPDS.

\subsection{Safety-Based Transformation}

It is expected that by improving the quality of the production system, safety can be significantly improved [45]. By introducing the T-view on LPDS, it is possible to increase the clarity of conversions in different phases of the project at the front-end of the project. For this purpose, it would be possible to take advantage of the existing methods available in this field, such as Building Information Modelling (BIM). The striking point here is how the transformation can be implemented in the safest possible way. One of the possible solutions can be modularization and pre-fabrication, which can reduce a significant portion of the site's risks and incidents. On the other hand, by defining the work breakdown structure and determining different work packages during the life cycle of the project-including the stages of construction, operation, and recycling - we can estimate the probable risks of accidents in each work package, and provide an optimal safety strategy in accordance with each package (Figure 4A). For example, Aslesen et al. [46] developed a model for integrating safety analyses, with systematic 
planning of production progress. In this model, certain principles were attached to each of the planning levels in the system of collaborative planning with respect to factors such as extra considerations towards WBS, to avoid hidden hazards.

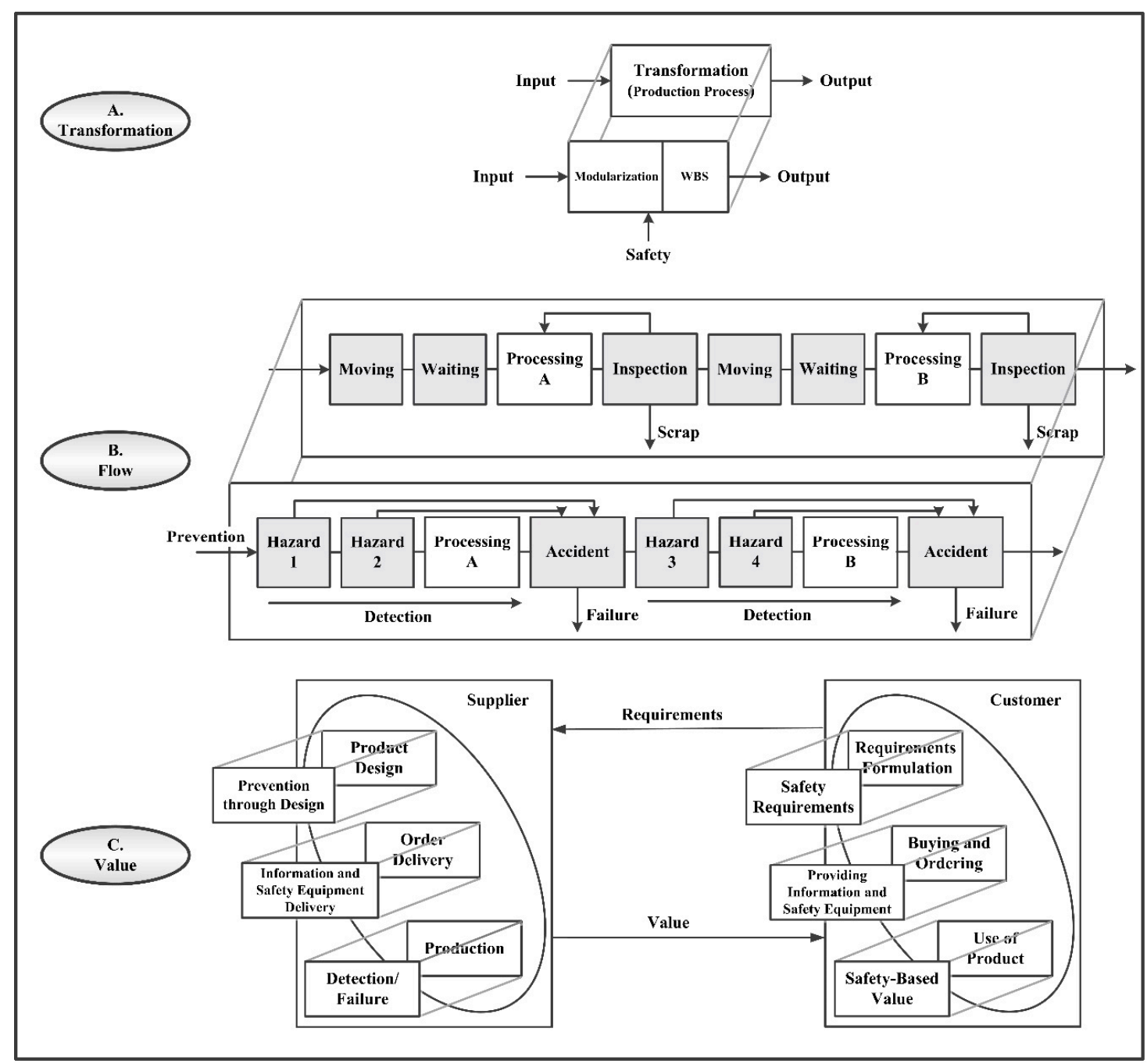

Figure 4. Safety-based theory of lean construction.

\subsection{Safety-Based Flow}

In the flow view, it is desirable to improve the flow process, and to develop a reliable workflow that is dependent on waste (Muda), variability (Mura), and overburden to workers and machines (Muri), and on the other hand, reliable workflow cannot be achieved without safe work practices [19]. For example, Abdelhamid and Everett [47] asserted that the successful implementation of the lean approach, and developing a reliable workflow is dependent on the decrease in variability (Mura). Accordingly, they studied workers' physical performance degradation as one of the most important causes of variability.

Ohno [48] identified seven waste items, including: (1) rework, (2) overproduction, (3) inventory, (4) overprocessing, (5) motion, (6) transportation, and (7) waiting, and the loss of employee's potential was later added to the list by Womack \& Jones [49]. According to Waehrer et al. [2], the cost of injury was about $15 \%$ of the total cost incurred in private industries in the US. Therefore, it is worthwhile to consider accidents as one of the most serious sources of waste in the construction industry. In this regard, it is proposed to add accidents as the ninth source of waste. We contend that the evaluation of the eight possible cases of waste cannot be accurate without considering safety, and any attempt to 
reduce them may result in damage to the safety performance of the project. That is, some of them may not be considered as waste if we look at them through the lens of safety. For example, the route that is designed for the movement of machinery at the site can be different in length depending on whether it is viewed through the lens of safety or not. In this regard, safe planning may result in a longer route to mitigate the risk of crashes with other vehicles or site workers; however, without considering this risk of accident, the shortest route may be preferred and any extra movements may be considered as waste.

Another point that can be taken into account in this view is CoS. As stated earlier, CoS considers four sources of cost, including the cost of prevention and inspection, and internal and external failure costs [38]. One of the points which is addressed in Figure 4B is the possibility of preventing some of the incidents that are predictable through preventative measures at the start of the process. When the necessary measures to prevent accidents are not sufficient, it is more likely to have accidents. Safety risks can be identified and eliminated through inspection and detection measures. However, if the risks are not mitigated, they may eventually lead to an accident, in which case the project will bear the direct and indirect costs of the incident or failure. The point here is to estimate the optimal point in the conformance and non-conformance costs of safety.

\subsection{Safety-based Value Creation}

As discussed in the previous sections, if we can change the client's point of view on safety, we can expect to improve safety performance. To this end, the concept of $\mathrm{V}$ can be used, because its main purpose is to create value for the customer. The remarkable point here is the possibility for identifying and extracting this value. In this regard, it is necessary to pay attention to a few points. Firstly, the value should be defined in the long run, because in some cases, the short-term view for safety performance improvement will be considered a costly activity. However, studies have shown that with a long-term approach, incident costs are far higher than prevention costs [39]. Therefore, finding the optimal point in this regard is necessary. Secondly, in addition to paying attention to creating value for the customer, the value required for stakeholders should also be considered. Finally, it should be noted that the definition of value is long-term, and it can be integrated among all stakeholders when it is possible to have all the stakeholders as an integrated team. To achieve this, the LPDS approach can be used. In order to examine the concept of $\mathrm{V}$ from the point of view of safety, the concept of $\mathrm{CoS}$ can also be used. The CoS is equal to the total cost of prevention and inspection, and the direct and indirect costs of incidents. Each organization must determine its risk appetite and risk tolerance according to its strategies, and then find the optimum $\mathrm{CoS}$ in the organization [38]. For example, in some projects, the achievement of zero-accident may even be desirable [39]. Therefore, in this context, it is important to achieve customer requirements and to create the highest value for the customer (Figure 4C).

\section{Conclusions}

In this study, we reviewed the literature related to the challenges of the implementation of safety in construction projects, and the principles related to lean construction, and then we examined the interaction effects of applying these two approaches to each other. In this regard, the effects of using LPDS on PtD implementation and safety improvements of the project was studied. In addition, the TFV theory was reviewed through the lens of safety. Studies have shown that key stakeholders can be entered into the project through LPDS, and as a result, they can create an integrated team with effective communications, in which all the key stakeholders are engaged in the risk-taking and benefits of the project, and can view themselves as being responsible for each other's performance. As a result, some of the obstacles to implementing PtD, such as the knowledge gap between designers and contractors on the design and construction of safe sites and workplaces, and lack of motivation in designers for getting involved in safety management processes can be solved. In addition, the use of LPDS enables the project participants to facilitate the creation of a positive safety climate in the project, by creating a collaborative environment between stakeholders, and creating a long-term vision based on the life cycle analysis of the project, including all stages of design, construction, operation, and recycling. Given the 
rapid growth of industries and the growing importance of resources, today, increasing the productivity of projects is more necessary than ever. With regard to the ability to influence the lean principles and techniques in improving project performance, it is expected that using the approach presented in this paper to combine the underlying principles of lean construction with safety principles can be a positive step towards improving safety, and consequently, improve the productivity of construction projects. It is also expected that the proposed model provides new insights into the field of lean construction and safety. Future research may investigate the details of this model and its practical implementation through empirical study.

Author Contributions: "S.M. reviewed the relevant literature and developed the conceptual framework; S.Y.B. adjusted the conceptual framework and M.M. contributed to the discussion."

Funding: This research received no external funding.

Conflicts of Interest: The authors declare no conflict of interest.

\section{References}

1. Murie, F. Building Safety-An International Perspective. Int. J. Occup. Environ. Health 2007, 13, 5-11. [CrossRef] [PubMed]

2. Waehrer, G.M.; Dong, X.S.; Miller, T.; Haile, E.; Men, Y. Costs of Occupational Injuries in Construction in the United States. Accid. Anal. Prev. 2007, 39, 1258-1266. [CrossRef] [PubMed]

3. Behm, M. Linking Construction Fatalities to the Design for Construction Safety Concept. Saf. Sci. 2005, 43, 589-611. [CrossRef]

4. Manuele, F.A. Prevention through Design (PtD): History and Future. J. Saf. Res. 2008, 39, 127-130. [CrossRef] [PubMed]

5. Levy, S.M. Project Management in Construction; McGraw-Hill Professional Engineering: New York, NY, USA, 2012.

6. Krafcik, J.F. Triumph of the Lean Production System. Sloan Management Review. 1988, 30, 41-52.

7. Womack, J.P.; Jones, D.T.; Roos, D. The Machine That Changed the World: The Story of Lean Production: How Japan's Secret Weapon in the Global Auto Wars Will Revolutionize Western Industry; Rawson Associates: New York, NY, USA, 1990.

8. Koskela, L. Application of the New Production Philosophy to Construction; Stanford University Stanford: University, CA, USA, 1992.

9. Koskela, L. An Exploration Towards a Production Theory and Its Application to Construction; VTT Technical Research Centre of Finland: Espoo, Finland, 2000.

10. Salem, O.; Solomon, J.; Genaidy, A.; Minkarah, I. Lean Construction: From Theory to Implementation. J. Manag. Eng. 2006, 22, 168-175. [CrossRef]

11. Nahmens, I.; Ikuma, L.H.; Khot, D. Kaizen and Job Satisfaction-A Case Study in Industrialized Homebuilding. Lean Constr. J. 2012, 91-104. Available online: https:/ / www.leanconstructionjournal.org/ (accessed on 5 January 2019).

12. Diekmann, J.E.; Krewedl, M.; Balonick, J.; Stewart, T.; Won, S. Application of Lean Manufacturing Principles to Construction; Construction Industry Institute: Boulder, CO, USA, 2004; p. 191.

13. Kung, D.; Alex, D.P.; Al-Hussein, M.; Fernando, S. Application of lean thinking to improve the productivity of water and sewer service installations. Can. J. Civ. Eng. 2008, 35, 418-430. [CrossRef]

14. Leonard, D. Building Quality at Veridian Homes. Qual. Prog. 2006, 39, 49.

15. Cho, S.; Ballard, G. Last Planner and Integrated Project Delivery. Lean Constr. J. 2011, 67-78.

16. Ballard, G. The Last Planner System of Production Control; University of Birmingham: Birmingham, UK, 2000.

17. Matthews, O.; Howell, G.A. Integrated Project Delivery an Example of Relational Contracting. Lean Constr. J. 2005, 2, 46-61.

18. Ballard, G. Lean Project Delivery System; White Paper No. 8; Lean Construction Institute: Berkeley, CA, USA, 2000.

19. Schafer, D.; Abdelhamid, T.S.; Mitropoulos, P.; Howell, G.A. Resilience Engineering: A New Paradigm For Safety In Lean Construction Systems. In Proceedings of the 16th Annual Conference of the International Group for Lean Construction, Manchester, UK, 16-18 July 2008. 
20. Nahmens, I.; Ikuma, L.H. An Empirical Examination of the Relationship between Lean Construction and Safety in the Industrialized Housing Industry. Lean Constr. J. 2009, 1-12.

21. Antillon, E.I.; Alarcon, L.F.; Hallowell, M.R.; Molenaar, K.R. A Research Synthesis on the Interface Between Lean Construction and Safety Management. In Proceedings of the 19th Annual Conference of the International Group for Lean Construction, Lima, Peru, 13-15 July 2011.

22. Howell, G.; Ballard, G.; Demirkesen, S. Why Lean Projects Are Safer. In Proceedings of the 25th Annual Conference of the International Group for Lean Construction, Herak-lion, Greece, 4-12 July 2017.

23. Martínez-Aires, M.D.; López-Alonso, M.; Martínez-Rojas, M. Building Information Modeling and Safety Management: A Systematic Review. Saf. Sci. 2018, 101, 11-18. [CrossRef]

24. Gambatese, J.A.; Pestana, C.; Lee, H.W. Alignment Between Lean Principles and Practices and Worker Safety Behavior. J. Constr. Eng. Manag. 2016, 143, 04016083. [CrossRef]

25. Ikuma, L.H.; Nahmens, I.; James, J. Use of Safety and Lean Integrated Kaizen to Improve Performance in Modular Homebuilding. J. Constr. Eng. Manag. 2010, 137, 551-560. [CrossRef]

26. Langford, D.; Rowlinson, S.; Sawacha, E. Safety Behaviour and Safety Management: Its Influence on the Attitudes of Workers in the UK Construction Industry. Eng. Constr. Archit. Manag. 2000, 7, 133-140. [CrossRef]

27. Wiegmann, D.A.; Zhang, H.; Von Thaden, T.L.; Sharma, G.; Gibbons, A.M. Safety Culture: An Integrative Review. Int. J. Aviat. Psychol. 2004, 14, 117-134. [CrossRef]

28. Mohamed, S. Safety Climate in Construction Site Environments. J. Constr. Eng. Manag. 2002, 128, 375-384. [CrossRef]

29. Gao, R.; Chan, A.P.; Utama, W.P.; Zahoor, H. Multilevel Safety Climate and Safety Performance in the Construction Industry: Development and Validation of a Top-Down Mechanism. Int. J. Environ. Res. Public Health 2016, 13, 1100. [CrossRef]

30. Zhou, Z.; Goh, Y.M.; Li, Q. Overview and Analysis of Safety Management Studies in the Construction Industry. Saf. Sci. 2015, 72, 337-350. [CrossRef]

31. Hinze, J. Construction Safety; Prentice Hall: Englewood Cliffs, NJ, USA, 2006.

32. Malekitabar, H.; Ardeshir, A.; Sebt, M.H.; Stouffs, R. Construction Safety Risk Drivers: A BIM Approach. Saf. Sci. 2016, 82, 445-455. [CrossRef]

33. Abdelhamid, T.S.; Everett, J.G. Identifying Root Causes of Construction Accidents. J. Constr. Eng. Manag. Asce 2000, 126, 52-60. [CrossRef]

34. Gambatese, J.; Hinze, J. Addressing Construction Worker Safety in the Design Phase: Designing for Construction Worker Safety. Autom. Constr. 1999, 8, 643-649. [CrossRef]

35. Huang, X. The Owner's Role in Construction Safety; University of Florida: Gainesville, FL, USA, 2003.

36. Soyka, P.A.; Feldman, S.J. Capturing the Business Value of EH\&S Excellence. Corp. Environ. Strategy 1998, 5, 6152-6168.

37. Chalos, P. Managing Cost in Today's Manufacturing Environment; Prentice Hall: Englewood Cliffs, NJ, USA, 1992.

38. Behm, M.; Veltri, A.; Kleinsorge, I.K. The Cost of Safety: Cost Analysis Model Helps Build Business Case for Safety. Prof. Saf. 2004, 49, 22.

39. Panopoulos, G.D.; Booth, R.T. An Analysis of the Business Case for Safety: The Costs of Safety-Related Failures and the Costs of their Prevention. Policy Pract. Health Saf. 2007, 5, 61-73. [CrossRef]

40. Koskela, L.; Howell, G.; Ballard, G.; Tommelein, I. The Foundations of Lean Construction. In Design and Construction: Building in Value; Butterworth Heinemann: London, UK, 2002; pp. 211-226.

41. Gunduz, M.; Fahmi Naser, A. Cost Based Value Stream Mapping as a Sustainable Construction Tool for Underground Pipeline Construction Projects. Sustainability 2017, 9, 2184. [CrossRef]

42. Andújar-Montoya, M.D.; Gilart-Iglesias, V.; Montoyo, A.; Marcos-Jorquera, D. A Construction Management Framework for Mass Customisation in Traditional Construction. Sustainability 2015, 7, 5182-5210. [CrossRef]

43. Grubbström, R.W. Modelling Production Opportunities-An Historical Overview. Int. J. Prod. Econ. 1995, 41, 1-14. [CrossRef]

44. American-Institute-of-Architects. Integrated Project Delivery: A Guide; Electronic, American Institute of Architects: Washington, DC, USA, 2007; p. 62. 
45. Mitropoulos, P. Production control and safety management as project safety determinants. In Proceedings of the 20th Annual Conference of the International Group for Lean Construction, San Diego, CA, USA, 18-20 July 2012.

46. Aslesen, S.; Sandberg, E.; Stake, S.; Bolviken, T. Integrating Safety Analyses in Production Planning and Control-A Proposal. In Proceedings of the 21st Annual Conference of the International Group for Lean Construction, Fortaleza, Brazil, 29 July-2 August 2013.

47. Abdelhamid, T.S.; Everett, J.G. Physical Demands of Construction Work: A Source of Workflow Unreliability. In Proceedings of the 10th Annual Conference of the International Group for Lean Construction, Gramado, Brazil, 6-8 August 2002.

48. Ohno, T. Toyota Production System: Beyond Large-Scale Production; CRC Press: Boca Raton, FL, USA, 1988.

49. Womack, J.P.; Jones, D.T. Lean Thinking-Banish Waste and Create Wealth in Your Corporation; Simon and Schuster: New York, NY, USA, 1996.

(C) 2019 by the authors. Licensee MDPI, Basel, Switzerland. This article is an open access article distributed under the terms and conditions of the Creative Commons Attribution (CC BY) license (http://creativecommons.org/licenses/by/4.0/). 